\title{
Editorial \\ Selective Catalytic Reduction: From Basic Science to deNOx Applications
}

\author{
Feng Gao ${ }^{1, *(1)}$ and Todd J. Toops ${ }^{2, *}$ \\ 1 Institute for Integrated Catalysis, Pacific Northwest National Laboratory, P.O. Box 999, \\ Richland, WA 99354, USA \\ 2 Oak Ridge National Laboratory, Oak Ridge, TN 37831, USA \\ * Correspondence: feng.gao@pnnl.gov (F.G.); toopstj@ornl.gov (T.J.T.); Tel.: +1-509-371-7164 (F.G.); \\ $+1-865-341-1207$ (T.J.T.)
}

Citation: Gao, F; Toops, T.J. Selective Catalytic Reduction: From Basic Science to deNOx Applications. Catalysts 2021, 11, 250. https:// doi.org/10.3390/catal11020250

Received: 9 February 2021

Accepted: 10 February 2021

Published: 12 February 2021

Publisher's Note: MDPI stays neutral with regard to jurisdictional claims in published maps and institutional affiliations.

Copyright: (C) 2021 by the authors. Licensee MDPI, Basel, Switzerland. This article is an open access article distributed under the terms and conditions of the Creative Commons Attribution (CC BY) license (https:/ / creativecommons.org/licenses/by/ $4.0 /)$.
The combustion of coal, petroleum and biofuel for energy generation has resulted in unprecedented benefits to the prosperity of our modern society and will continue to do so in the future. However, rapid global climate changes, especially frequent extreme weather conditions that we have witnessed in the past two decades, remind us how fragile our planet is, and how important sustainable development is for future generations. The advancement of sciences and technologies for environmental protection, such as water purification, soil detoxification, volatile organic compounds (VOC) decomposition, plastic waste control and combustion emission control, is key for sustainability. With global awareness of the importance of environmental protection and sustainable energy development in legislation, the scientific community and the general public, we all have reasons to believe success is achievable in the 21st century.

Among the various deNOx techniques, selective catalytic reduction (SCR) has been particularly successful. Oxide-based SCR was first commercialized in the 1970s; much more recently, zeolite-based catalysts were deployed in 2010 [1-4]. Such a success is a result of continuing research on the basic sciences of this catalytic chemistry, and the accompanying catalyst synthesis and development of auxiliary techniques (e.g., $\mathrm{NH}_{3}$ delivery) that facilitate this catalytic chemistry. The 12 original papers and review articles of this Special Issue, contributed by $\sim 60$ authors from both academia and industry, nicely reflect this continuing effort.

Four review articles are included here, two on oxide-based catalysts and two on zeolite-based catalysts. The review article by Shan, He and coworkers [5] summarized recent progress on low-temperature activity of vanadia-based SCR catalysts, including catalyst modification with metal oxides and other elements, the use of novel supports, the application of novel synthesis approaches and the use of vanadium precursors in different forms. The authors also addressed recent advances in understanding low-temperature reaction mechanisms, and finally discussed opportunities and challenges of vanadia-based catalysts in future research. Liu and coworkers [6] reviewed the latest research on $\mathrm{SO}_{2}$ resistance of oxide-based SCR catalysts. The authors first summarized possible catalyst deactivation mechanisms in $\mathrm{SO}_{2}$-containing flue gas, followed by presenting strategies for alleviating such deactivation, including modification of the catalyst supports, applying complex oxide catalysts, optimizing catalyst preparation methods and catalyst acidification. The authors further summarized mechanisms for improving sulfur resistance and provided suggestions for further catalyst development.

Regarding zeolite-based SCR, Chen and collaborators [7] provided a review on recent understanding about active site dynamics in Cu-chabazite catalysts, in particular at low reaction temperatures. The authors first summarized recent advances in theoretical studies in low-temperature $\mathrm{Cu}$ dynamics, in particular work with ab initio molecular dynamics (AIMD) or metadynamics simulations, and then reviewed recent spectroscopic studies to follow the evolution of the coordinative environment and the local structure 
of $\mathrm{Cu}$ centers during low-temperature $\mathrm{NH}_{3}-\mathrm{SCR}$ reactions. These were then followed by presenting how understanding $\mathrm{Cu}$ dynamics is essential for low-temperature $\mathrm{Cu}$ redox, solid-state ion exchange catalyst synthesis and direct monitoring of $\mathrm{NH}_{3}$ storage and conversion. Finally, the authors discussed new perspectives in manipulating $\mathrm{Cu}$ dynamics to improve low-temperature $\mathrm{NH}_{3}$-SCR efficiency as well as in understanding other important reactions. Finally, the review article by Gao [8] summarized recent studies on Fe-exchanged small-pore zeolite SCR catalysts. This summary included the synthesis approach of small-pore $\mathrm{Fe}$ /zeolites, the nature of the SCR-active Fe-species in these catalysts as determined by experimental and theoretical approaches, Fe-species transformation during hydrothermal aging, SCR reactions/structure-function correlations and a few aspects on industrial applications.

Among the eight original articles, four of them focused on new catalyst design, characterization and performance evaluation; one on in situ $\mathrm{SO}_{2}$ poisoning; one on integrated catalyst design; one on SCR system dynamic modeling; and, finally, one on urea injection. As Guest Editors, we are pleased to see the breadth of these research topics that nicely reflect the healthy development of SCR science and technology from various approaches.

Work by Liu and coworkers [9] investigated a sulfated $\mathrm{Fe}_{2} \mathrm{O}_{3} \mathrm{SCR}$ catalyst supported on $\mathrm{TiO}_{2}$. The authors discovered that the catalyst surface composition is influenced by different sequences of precursor introduction during catalyst synthesis, where catalysts with coexisting isolated $\mathrm{Fe}_{2} \mathrm{O}_{3}$ and $\mathrm{SO}_{4}{ }^{2-}$ domains on the surface, or predominant $\mathrm{SO}_{4}{ }^{2-}$ domain on the surface, can be readily prepared. The authors further demonstrated that such a catalyst surface composition difference affects redox capacity, $\mathrm{NH}_{3}$ adsorption and SCR mechanisms. Wang and coworkers reported [10] the preparation and application of Sb-containing SbZrOx, SbCeOx and SbCeZrOx SCR catalysts. Via the application of a number of chemical titration and spectroscopic methods to study their catalysts, the authors demonstrated that $\mathrm{Sb}$ introduction influences acid distribution and redox properties, which in turn affect $\mathrm{NH}_{3}$ adsorption and $\mathrm{NO}$ oxidation. The authors suggested that "dual active sites" favor $\mathrm{NH}_{3}$ adsorption and nitrate formation, and their $\mathrm{SbCeZrOx}$ catalyst displayed the most balanced dual site functions and, thus, the best SCR performance.

He and coworkers [11] studied the promoting effect of Mn on a Cu-SSZ-13 catalyst. The authors discovered that impregnated MnOx species caused a decline in the crystallinity of Cu-SSZ-13 but markedly improved the redox ability. Nitrate and nitrite species were observed in the Mn-modified Cu-SSZ-13, and they suggested that the formation of these species caused the observed increase in low-temperature $\mathrm{NH}_{3}-\mathrm{SCR}$ activity. They further proposed that the addition of $\mathrm{Mn}$ is a promising method for promoting the low-temperature catalytic activity of Cu-SSZ-13. In studying the in situ $\mathrm{SO}_{2}$ poisoning mechanism of $\mathrm{Cu}$ SSZ-13, Zhang and coworkers [12] demonstrated that the formation of sulfate species, including $\left(\mathrm{NH}_{4}\right)_{2} \mathrm{SO}_{4}, \mathrm{CuSO}_{4}$ and $\mathrm{Al}_{2}\left(\mathrm{SO}_{4}\right)_{3}$, are temperature dependent, where a high temperature only favors the formation of the latter two species. The authors further demonstrated that $\mathrm{SO}_{2}$ has a negative effect on low-temperature catalytic performance due to the sulfation of active sites; however, a positive effect is found at a high temperature, owing to the inhibition of the $\mathrm{NH}_{3}$ oxidation reaction. In joint research between industry and academia, Ogura and coworkers [13] investigated various Cu-zeolites (zeolite mining), and demonstrated the suitability of $\mathrm{Cu}$-exchanged zeolite AFX as a selective and stable SCR catalyst.

It is important to realize that efforts in designing new catalysts and enhancing existing catalysts must be accompanied by many other R\&D efforts in order to achieve optimal deNOx efficiency. In this regard, three more highly valuable contributions were provided. Work by Li, Yu and collaborators [14] demonstrated the fabrication of a large V-based catalyst filter to simultaneously remove NOx, SOx and dust. Yan, Sun and coworkers [15] discussed a dynamic model that was incorporated with delay estimation and variable selection to analyze outlet $\mathrm{NOx}$ emissions and $\mathrm{NH}_{3}$ injection. Finally, a study by Lim and coworkers [16] on urea spray uniformity from two different urea injectors broadened the scope and increased the overall readership of this Special Issue. 
Funding: The authors were funded by the U.S. Department of Energy (DOE), Energy Efficiency and Renewable Energy, Vehicle Technologies Office.

Acknowledgments: We would like to close by thanking all authors that contributed to this Special Issue. We are honored to be invited as Guest Editors. We are also thankful to Keith Hohn, the Editor-in-Chief for the Catalysts journal, and our gratitude also goes to other staff of the journal that made our work smooth and joyful. Particularly, it has been a great pleasure working with Adela Liao, the Managing Editor for this Special Issue.

Conflicts of Interest: The authors declare no conflict of interest.

\section{References}

1. Pârvulescu, V.I.; Grange, P.; Delmon, B. Catalytic removal of NO. Catal. Today 1998, 46, 233-316. [CrossRef]

2. Nova, I.; Tronconi, E. Urea-SCR Technology for deNOx after Treatment of Diesel Exhausts; Springer Science \& Business Media: New York, NY, USA, 2014.

3. Beale, A.M.; Gao, F.; Lezcano-Gonzalez, I.; Peden, C.H.F.; Szanyi, J. Recent advances in automotive catalysis for NOx emission control by small-pore microporous materials. Chem. Soc. Rev. 2015, 44, 7371-7405. [CrossRef] [PubMed]

4. Paolucci, C.; di Iorio, J.R.; Ribeiro, F.H.; Gounder, R.; Schneider, W.F. Catalysis science of NOx selective catalytic reduction with ammonia over Cu-SSZ-13 and Cu-SAPO-34. Adv. Catal. 2016, 59, 1-107.

5. Lian, Z.H.; Li, Y.J.; Shan, W.P.; He, H. Recent progress on improving low-temperature activity of vanadia-based catalysts for the selective catalytic reduction of NOx with ammonia. Catalysts 2020, 10, 1421. [CrossRef]

6. Liu, C.X.; Wang, H.J.; Zhang, Z.Y.; Liu, Q.L. The latest research progress of $\mathrm{NH}_{3}-\mathrm{SCR}$ in the $\mathrm{SO}_{2}$ resistance of the catalyst in low temperatures for selective catalytic reduction of NOx. Catalysts 2020, 10, 1034. [CrossRef]

7. Lei, H.R.; Rizzotto, V.; Guo, A.Q.; Ye, D.Q.; Simon, U.; Chen, P.R. Recent understanding of low-temperature comer dynamics in $\mathrm{Cu}$-chabazite $\mathrm{NH}_{3}$-SCR catalysts. Catalysts 2021, 11, 52. [CrossRef]

8. Gao, F. Fe-exchanged small-pore zeolites as ammonia selective catalytic reduction $\left(\mathrm{NH}_{3}-\mathrm{SCR}\right)$ catalysts. Catalysts 2020 , 10, 1324. [CrossRef]

9. Fan, B.Y.; Zhang, Z.Y.; Liu, C.X.; Liu, Q.L. Investigation of sulfated iron-based catalysts with different sulfate position for selective catalytic reduction of NOx with $\mathrm{NH}_{3}$. Catalysts 2020, 10, 1035. [CrossRef]

10. Xu, Q.; Liu, D.D.; Wang, C.C.; Zhang, W.C.; Guo, Y.L.; Guo, Y.; Wang, L.; Ke, Q.P.; Ha, M.N. Sb-containing metal oxide catalysts for the selective catalytic reduction of $\mathrm{NOx}$ with $\mathrm{NH}_{3}$. Catalysts 2020, 10, 1154. [CrossRef]

11. Du, J.P.; Wang, J.Y.; Shi, X.Y.; Shan, Y.L.; Zhang, Y.; He, H. Promoting effect of Mn on in situ synthesized Cu-SSZ-13 for NH $3-S C R$. Catalysts 2020, 10, 1375. [CrossRef]

12. Qiu, Y.; Fan, C.; Sun, C.C.; Zhu, H.C.; Yi, W.T.; Chen, J.Z.; Guo, L.Y.; Niu, X.X.; Chen, J.J.; Peng, Y.; et al. New insight into the in situ $\mathrm{SO}_{2}$ poisoning mechanism over Cu-SSZ-13 for the selective catalytic reduction of $\mathrm{NOx}_{\text {with }} \mathrm{NH}_{3}$. Catalysts 2020, 10, 1391. [CrossRef]

13. Ogura, M.; Shimada, Y.; Ohnishi, T.; Nakazawa, N.; Kubota, Y.; Yokoi, T.; Ehara, M.; Shimizu, K.; Tsunoji, N. AFX zeolite for use as a support of $\mathrm{NH}_{3}$-SCR catalyst mining through AICE joint research project of industries-academia-academia. Catalysts 2021, 11, 163. [CrossRef]

14. Lin, H.F.; Chen, Z.H.; Li, C.M.; Yan, X.L.; Yao, Z.L.; Xu, G.W.; Gao, S.Q.; Huang, X.; Yu, J. The denitration and dedusting behavior of catalytic filter and its industrial application in glass kilns. Catalysts 2020, 10, 1394.

15. Dong, Z.; Li, L.; Yan, L.Q.; Sun, M.; Li, J.S. A dynamic model incorporated with delay estimation and variable selection for control of SCR De-NOx process. Catalysts 2020, 10, 1364. [CrossRef]

16. Wardana, M.K.A.; Oh, K.; Lim, O. Investigation of urea uniformity with different types of urea injectors in an SCR system. Catalysts 2020, 10, 1269. [CrossRef] 